\title{
Sugar and Fat: Sensory and Hedonic Evaluation of Liquid and Solid Foods
}

\author{
ADAM DREWNOWSKI ${ }^{1}$ \\ Human Nutrition Program, School of Public Health and Department of Psychiatry \\ Medical School, The University of Michigan, Ann Arbor, MI 48109 \\ E. EILEEN SHRAGER, CAREN LIPSKY, ELIOT STELLAR \\ Obesity Research Group, University of Pennsylvania, Philadelphia, PA 19104
}

AND

M. R. C. GREENWOOD

Department of Biology, Vassar College, Poughkeepsie, NY 12601

Received 20 May 1988

\begin{abstract}
DREWNOWSKI, A., E. E. SHRAGER, C. LIPSKY, E. STELLAR AND M. R. C. GREENWOOD. Sugar and fat: Sensory and hedonic evaluation of liquid and solid foods. PHYSIOL BEHAV 45(1) 177-183, 1989.-Twenty-five subjects evaluated the sweetness, creaminess and fat content of liquid and solid dairy products containing between 0.1 and $52 \mathrm{~g}$ fat $100 \mathrm{~g}$ and sweetened with 0-20\% sucrose weight/weight. Liquid stimuli included skim milk, whole milk, half and half, and heavy cream, while the solids included cottage cheese and cream cheese, blended and spread "jelly-roll" fashion on slices of white bread. The subjects' ratings of stimulus sweetness, creaminess, and fat content differed sharply between liquids and solids, and the assessment of fat content of solid foods appeared to be impaired. In contrast, acceptability ratings for both sets of stimuli were not substantially different: the subjects optimally preferred equivalent levels of sugar in both liquids and solids, but selected higher fat levels in solid than in liquid foods. Sensory preferences for fat in liquid stimuli may not always be indicative of preferences for fat in solid foods.
\end{abstract}

Sugar and fat Sensory and hedonic evalution Response surface method

TASTE preferences for sweet solutions are commonly assumed to be indicative of sensory preferences for sweetened solid foods $(2,22)$. The chief rationale behind studies on sweet taste preferences among children, adolescents and adults has been the belief that sensory preference data can serve as a potential index of food choice and therefore food consumption $(17,22)$. Numerous studies on obesity and sweet taste have treated taste preferences for sweet solutions as an index of caloric repletion and the physiological or nutritional status of the organism $(5,9,17)$.

However, it should be noted that the typical palatable "sweet" foods such as chocolate, ice cream, cakes and other desserts are almost invariably solids rather than liquids. Furthermore, such foods often contain fat (in combination with sugar) as a major ingredient and the principal source of calories (8). It is unclear whether liquid stimuli, and in particular sucrose solutions in water, should remain the stimulus of choice in the study of taste-related behaviors in human subjects.

Factors that influence the sensory acceptability of sweet solutions have been very extensively described in the scien- tific literature $(2,3,5,9,17,22)$. In contrast, very little is known about the sensory acceptability of dietary fats. Although fats determine the characteristic texture, flavor and aroma of many foods, there is little information about their sensory and hedonic characteristics $(6,8,10)$. The extent of human ability to assess the fat content of liquid or solid foods is unclear, and the relationship between perceived fat content and sensory acceptance of fat-rich foods is largely unexplored (10-12).

What oral sensations contribute to the perception of fat content? Sensory evaluation studies $(6-8,16,21)$ have shown that sensory assessment of fats largely depends on the evaluation of mouthfeel and texture, and to a lesser degree on olfaction. For liquid dairy products, where fat is contained in emulsified globules, the perception of "fatness" is commonly guided by the perception of stimulus smoothness or viscosity (16). The standard viscosity scale developed as part of the General Foods Texture Profile used as reference points such stimuli as cream, mayonnaise, or sweetened condensed milk containing different amounts of fat $(4,20$,

'Requests for reprints should be addressed to Adam Drewnowski, School of Public Health, University of Michigan. 
21). Studies on sensory evaluation of liquid dairy products have indicated that mouthfeel attributes of thickness, smoothness, and creaminess are all closely linked to the stimulus fat content (6-8).

The assessment of fat content of solid foods is more problematic. Fats contribute to food consistency and texture, and may endow the food with its mechanical and geometerical characteristics $(4,20)$, including food hardness, cohesiveness, adhesiveness, and viscosity as well as the shape, size and orientation of food particles (e.g., grainy, coarse). Mouthfeel characteristics of food generally refer to the perception of moisture or fat (e.g., wet, oily, greasy). Since fats in solid foods facilitate mastication and swallowing, their presence may become apparent only with time. Arguably, different sensory qualities may mediate the perception of fat in solid as opposed to liquid foods.

The acceptability of fat-containing foods is another issue for investigation. Unlike preferences for sugar in different food media, sensory preferences for dietary fats are likely to be system-specific. For example, high acceptability of highfat ice cream need not imply liking for greasy hamburgers. Unlike sugar, fat is often perceived as an integral part of the food itself, and the acceptability of fats is likely to vary widely between one food system and another. It is therefore important to extend studies on hedonic aspects of dietary fats to a wider range of foods, and to relate them where possible to actual measures of food intake.

Many nutritionists regard fats as "hidden calories" (13). The typical consumer, said to be unaware of the fat content of common foods, may unwittingly consume a palatable diet that is overly rich in fats (13). Given the current health emphasis on low-fat diets, and the development of fat substitutes there is a need for more basic studies on sensory and hedonic aspects of fats, and on the acceptability of high-fat foods.

The present study compared the ability of male and female subjects to evaluate the perceived sweetness, creaminess and fat content of selected liquid and solid foods. The subjects, first tested with sweetened mixtures of milk and cream were retested three months later with solid blends of cottage cheese and cream cheese of comparable sugar and fat contents.
TABLE 1

SUMMARY OF SUBJECT CHARACTERISTICS

\begin{tabular}{lrr}
\hline & $\begin{array}{c}\text { Men } \\
(\mathrm{n}=12)\end{array}$ & $\begin{array}{c}\text { Women } \\
(\mathrm{n}=13)\end{array}$ \\
\hline Weight (lb) & $168.6(4.2)$ & $131.7(3.4)$ \\
Height (in.) & $73.1(0.5)$ & $65.7(0.7)$ \\
BMI (kg/m $)$ & $22.1(0.4)$ & $21.4(0.5)$ \\
Age (years) & $20.1(0.7)$ & $19.2(0.3)$
\end{tabular}

The data are means (and SEMs).

METHOD

\section{Subjects}

Twenty-five young men and women of normal weight recruited by advertising among students at the University of Pennsylvania took part in the study in return for payment. The subjects' heights and weights were measured in the laboratory. All 25 subjects were initially tested using liquid foods (Test A). Three months later, all 13 women and 8 out of 12 men were retested using solid foods (Test B).

Subject characteristics are summarized in Table 1. Mean weights were $131.7 \mathrm{lb}$ for the women and $168.6 \mathrm{lb}$ for the men. These values are close to median weights for 18-24 year old men and women, as based on NHANES data and published by the National Center for Health Statistics (1). Values of the body mass index (BMI=weight/height $\left.{ }^{2}\right)$ were also in the normal range.

\section{Sensory Stimuli}

Liquid stimuli was previously described mixtures of milk, cream and sugar, containing between 0.1 and 52.6 percent fat weight by weight, and sweetened with $0,5,10$ or 20 percent sucrose $(12,13)$. Fat concentration of $52 \%$ was achieved by mixing heavy cream with a small amount $(15 \%)$ of safflower oil. Solid food stimuli included: skim milk cottage cheese $(<0.5 \%$ fat $w / w)$, whole milk cottage cheese ( $4 \%$ fat $)$, a 25:75

TABLE 2

SUMMARY OF EXPERIMENTAL DESIGN

\begin{tabular}{lccccc}
\hline & $\begin{array}{c}\text { Fat content } \\
(\mathbf{g} / 100 \mathrm{~g})\end{array}$ & $\begin{array}{c}\text { Sugar content } \\
(\% \text { wt/wt) }\end{array}$ \\
\hline Liquid food system & & & & & \\
skim milk & 0.1 & 0 & 5 & 10 & 20 \\
whole milk & 3.5 & 0 & 5 & 10 & 20 \\
half and half & 12.5 & 0 & 5 & 10 & 20 \\
heavy cream & 37.6 & 0 & 5 & 10 & 20 \\
heavy cream + oil & 52.6 & 0 & 5 & 10 & 20 \\
Solid food system (+ white bread) & 0.5 & & & & \\
skim milk cottage cheese & 4.0 & 0 & 5 & 10 & 20 \\
whole milk cottage cheese & 4.0 & 0 & 5 & 10 & 20 \\
cottage + cream cheese & 12.4 & 0 & 5 & 10 & 20 \\
cream cheese & 37.6 & 0 & 5 & 10 & 20 \\
cream cheese + shortening & 52.6 & 0 & 5 & 10 & 20 \\
\hline
\end{tabular}

Stimuli are $\mathbf{2 0}$ liquid or solid mixtures of dairy products and sucrose. 
mixture of cream cheese and $4 \%$ cottage cheese (12.4\% fat), cream cheese ( $37.6 \%$ fat) and a mixture of cream cheese and Crisco vegetable shortening (52.6\% fat). The solid samples were also sweetened with $0,5,10$ and $20 \%$ sucrose weight by weight. The sucrose and solid cheese mixtures were homogenized in a food processor and then spread on a flattened slice of white bread (Wonderbread) with crust removed, rolled up "jelly roll" fashion and cut into 8 pieces for use as test samples (19). Each solid food unit contained approximately $3.5 \mathrm{~g}$ of the sweetened cheese spread and $2.2 \mathrm{~g}$ of white bread (19). The composition of sensory stimuli is summarized in Table 2.

\section{Procedures}

Liquid samples ( $10 \mathrm{ml}$ volume), chilled to $5^{\circ} \mathrm{C}$ were presented to subjects in $30 \mathrm{ml}$ paper cups and in a random order. Subjects were asked to empty the contents of each cup into their mouths and hold the sample for as long as needed to make hedonic and perceptual judgments. The subjects then expectorated the sample and thoroughly rinsed their mouths with tap water. Comparable taste-and-spit procedures were followed with chilled solid food samples (mean wt. $5.7 \mathrm{~g}$ ) also kept in a refrigerator until the time of testing. Each sample was rated along 9-point category scales. Hedonic response was rated along a scale that ranged from "extremely unpleasant" to "extremely pleasant." Intensity of sweetness of cheese spread was rated along a 9-point scale ranging from "not at all sweet" to "extremely sweet." The scales for creaminess and fat content of the spread also ranged from "not at all -." to "extremely--." All subjects were tested in the morning, approximately 3 hours following their habitual breakfast meal.

\section{Data Analyses}

Since no significant differences in sensory perception or hedonic preference were observed between men and women, the data for both sexes were pooled for all analyses. Intensity estimates of product sweetness, creaminess and fat content were analyzed using BMDP ANOVA for repeated measures with stimulus consistency (liquid vs. solid) and fat and sugar levels as the principal variables. This ANOVA was based on the 21 subjects for whom the full set of data was available.

Hedonic response profiles were analyzed using two principal dependent variables: the magnitude of the pleasantness response, and the ingredient composition of the most pleasant-tasting mixture. Hedonic ratings were first analyzed using repeated measures ANOVA, with stimulus consistency, sugar and fat levels as the principal variables.

Further analyses addressed hedonic response profiles of individual subjects. To determine whether the optimally preferred levels of sugar or fat were the same for both liquids (Test A) and solids (Test B), maximal hedonic responses were plotted on Sugar and Fat Response Grids. The level of sugar or fat that was maximally preferred on Test A (liquid foods) was plotted along the vertical $y$-axis. The level of sugar or fat that was optimally preferred on Test B (solid foods) was plotted along the horizontal $x$-axis. Scores plotted along the diagonal represented the number of subjects who selected the same level of sugar or fat in both liquid and solid foods. The two Response Grids provide a visual representation of the stability of sensory preferences across the two sets of stimuli.

The second set of analyses determined the ingredient composition of the best-tasting mixture, as rated by individual subjects. Hedonic response profiles were modelled using a multivariate analytical procedure known as the Response Surface Method (10-12). The model assumes that hedonic response to a complex stimulus is a nonlinear function of perceived ingredient levels. For the present system of fat and sugar, each hedonic response $(\mathrm{H})$ was assumed to be a function of both sucrose $(S)$ and fat $(F)$ levels such that:

$$
\begin{aligned}
H= & a_{0}+a_{1}(\log S)+a_{2}(\log F) \\
+ & a_{3}(\log S)^{2}+a_{4}(\log F)^{2} \\
& +a_{5}(\log S)(\log F)
\end{aligned}
$$

After coefficient values $a_{0}$ through $a_{5}$ were determined by solving simultaneous equations, this algorithm was used to predict hedonic responses to a variety of sucrose (S) and fat (F) levels, including those not empirically tested. The model incorporates predicted data points among the 20 empirically obtained ones to yield a more accurate representation of the hedonic response profile than could be obtained on the basis of experimental data alone. Goodness of fit of the model was determined by the least squares method (11).

\section{RESULTS}

\section{Intensity Ratings}

As shown in Fig. 1, the perceived sweetness of liquid and solid stimuli rose with increasing sucrose concentration. The main effect of sugar was highly significant, $F(3,60)=139.64$, $p<0.01$. The perception of sweetness was masked somewhat by increasing stimulus fat content: the main effect of fat was also significant, $F(4,80)=3.29, p<0.05$, and there was a significant sugar by fat interaction, $\mathrm{F}(12,240)=1.82, p<0.05$.

Sweetness intensity functions for solids were less steep and spanned a much narrower range of the category scale relative to liquid stimuli. There was a strong main effect of stimulus consistency, $\mathrm{F}(1,20)=33.71, p<0.01$, and significant sugar by stimulus type, $\mathrm{F}(3,60)=24.63, p<0.01$, and fat by stimulus type interactions, $\mathrm{F}(4,80)=4.13, p<0.01$.

Perceived creaminess of liquid stimuli rose steeply with increasing fat content, as shown in Fig. 2. The main effect of fat was highly significant, $\mathrm{F}(4,80)=59.52, p<0.01$. It is worth noting that the addition of oil to heavy cream did not enhance its perceived creaminess. In contrast, the addition of sucrose to low-fat stimuli changed their viscosity, resulting in elevated ratings of creaminess, as reported by Drewnowski and Greenwood (11). The main effect of sucrose on ratings of creaminess was thus significant, $\mathrm{F}(3,60)=9.13, p<0.01$.

Creaminess functions for solid stimuli were not always monotonically increasing. Although the main effect of stimulus type was marginal, $\mathbf{F}(1,20)=3.99,0.05<p<0.01$, there was a strong fat by stimulus type interaction, $\mathrm{F}(4,80)=41.82, p<0.01$. Some subjects appeared to have considerable difficulty with this task, and their perception of stimulus creaminess was not linked to increasing stimulus fat content.

The perceived fat content of the stimuli rose with increasing fat levels, as shown in Fig. 3. The main effect of fat was again highly significant, $F(4,80)=50.50, p<0.01$, and no main effect of sucrose was observed. The subjects' ability to assess the fat content of solid as opposed to liquid foods was greatly impaired, as shown by a strong fat by stimulus type interaction, $\mathrm{F}(4,80)=24.77, p<0.01$. 


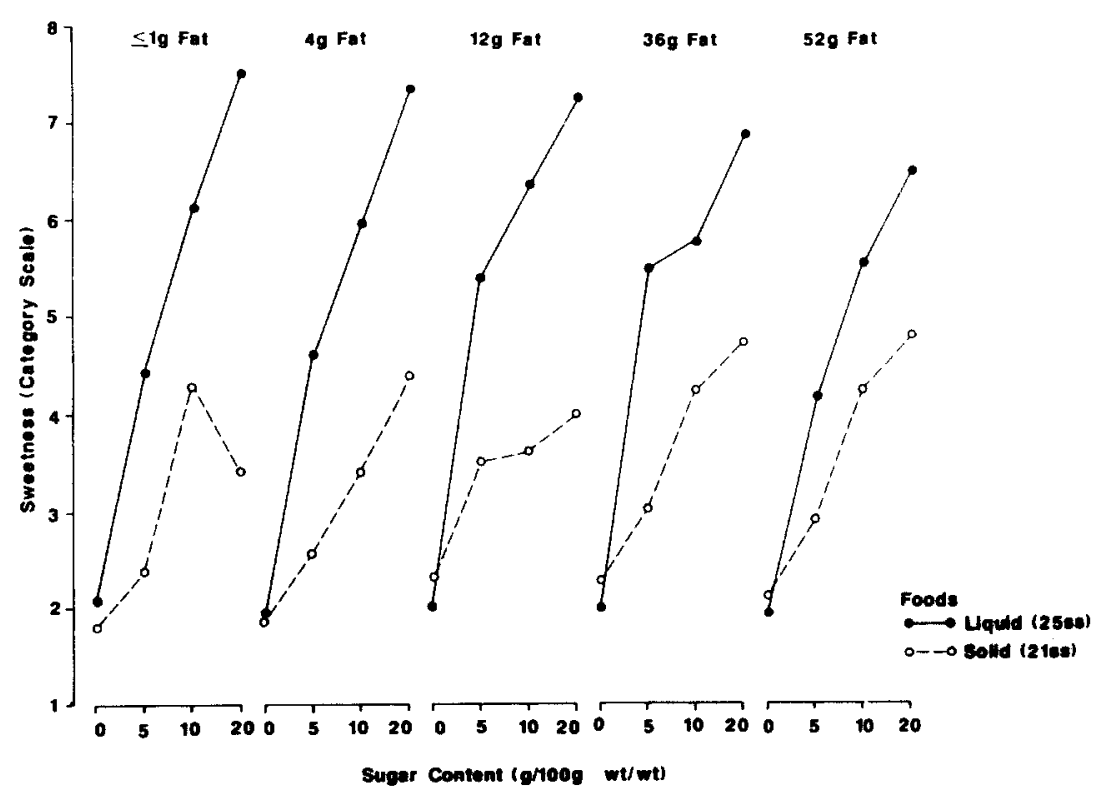

FIG. 1. Mean estimates of stimulus sweetness as a function of sucrose level for each type of dairy product. Sucrose levels are expressed as grams per $100 \mathrm{~g}$ (wt./wt.).

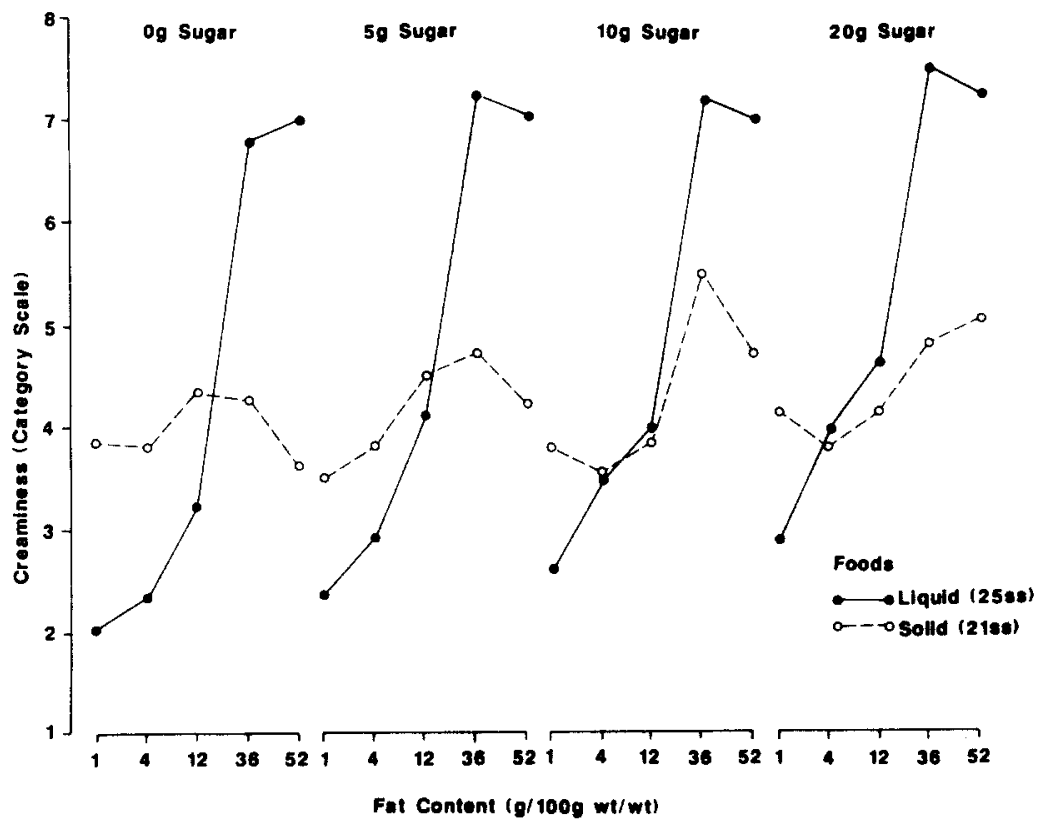

FIG. 2. Mean estimates of stimulus creaminess as a function of fat level for each level of sucrose. Fat content is expressed as grams per $100 \mathrm{~g}$ (wt./wt.).

\section{Hedonic Response}

Hedonic ratings for liquid and solid stimuli are summarized in Fig. 4. The acceptability of the stimuli depended on the relative proportions of sugar and fat. Main effects of both sugar, $F(3,60)=24.67, p<0.01$, and fat, $F(4,80)=3.64$, $p<0.01$, were significant, and there was a marginal sugar by fat interaction, $F(12,240)=1.78,0.05<p<0.01$. Acceptability ratings did not change with stimulus consistency, $F<1$, and the sugar by stimulus type interaction was not significant,
$F(3,60)=2.13$, ns. However, the fat by stimulus type interaction was significant, $F(4,80)=3.15, p<0.05$, sugesting that the subjects preferred solid foods that were richer in fat.

Highest acceptability ratings for liquid foods were obtained for half and half $(12 \mathrm{~g}$ fat $100 \mathrm{~g})$ sweetened with $5-10$ percent sugar. Increasing fat level beyond that point caused acceptability ratings to decline. In contrast, hiphest hedonic ratings for solid foods were obtained with mixtures in the range of $36-52 \mathrm{~g} / 100 \mathrm{~g}$ fat and 10 to 20 percent sugar. To 


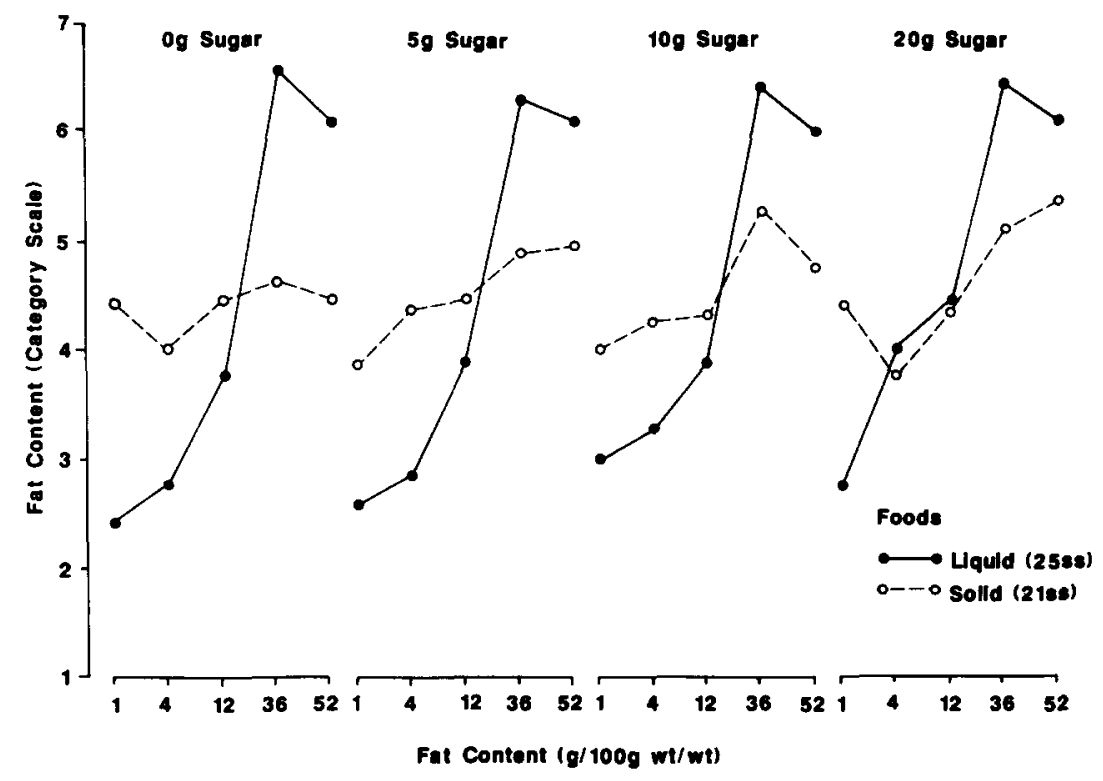

FIG. 3. Mean estimates of stimulus fat as a function of fat level at each level of sucrose. Fat content is expressed as grams per $100 \mathrm{~g}$ (wt./wt.).

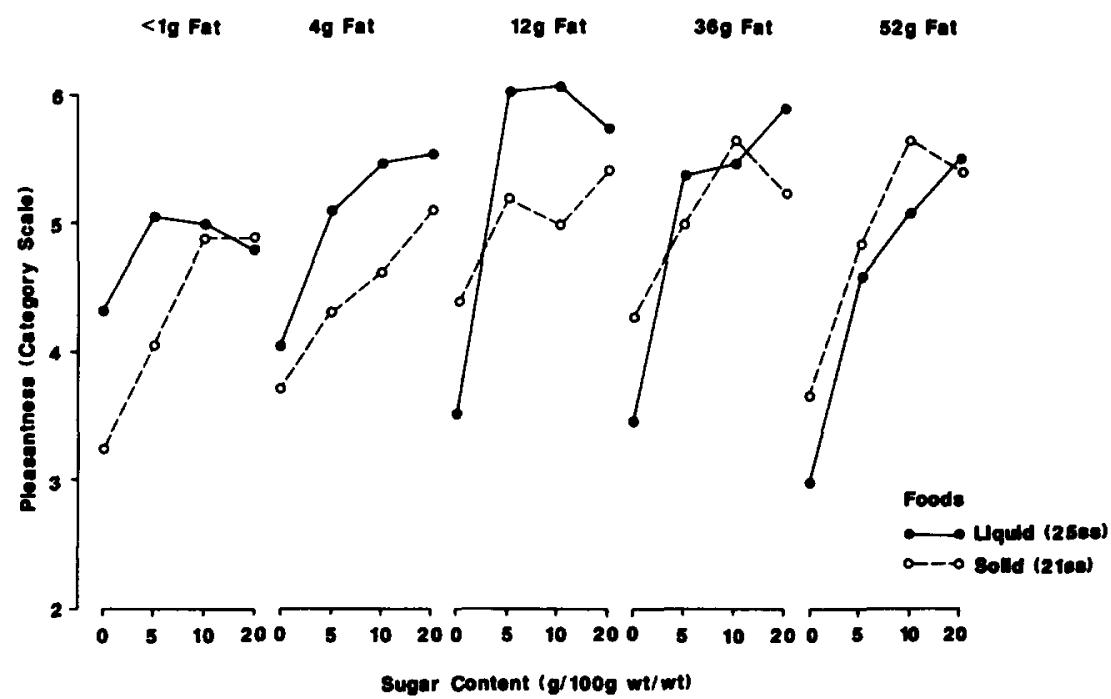

FIG. 4. Mean hedonic ratings as a function of sucrose content for each type of dairy product.

predict the ingredient composition of stimuli maximally liked by individual subjects, hedonic responses were modelled using the Response Surface Method (RSM).

Optimal sucrose and fat levels predicted by RSM are summarized in Table 3. For liquid foods (Test A), optimal sucrose level was $13 \%$, while optimal fat level was $20 \%$ figures in close agreement with a previous report (11). For solid foods (Test B), optimal sugar level was $16 \%$, while optimal fat level was $35 \%$. While optimal sugar levels were not significantly different between stimuli, optimal fat levels were significantly higher for solid than for liquid foods, $t(44)=2.45, p<0.05$.
TABLE 3

OPTIMALLY PREFERRED SUCROSE AND FAT LEVELS AS PREDICTED BY RSM

\begin{tabular}{lcccc}
\hline & \multicolumn{2}{c}{ Liquid Foods (Test A) } & \multicolumn{2}{c}{ Solid Foods (Test B) } \\
$\begin{array}{c}\text { Fat } \\
(\mathrm{g} / 100 \mathrm{~g})\end{array}$ & $\begin{array}{c}\text { Sugar } \\
(\mathrm{g} / 100 \mathrm{~g})\end{array}$ & $\begin{array}{c}\text { Fat } \\
(\mathrm{g} / 100 \mathrm{~g})\end{array}$ & $\begin{array}{c}\text { Sugar } \\
(\mathrm{g} / 100 \mathrm{~g})\end{array}$ \\
\hline Total: & $20.1(3.9)$ & $13.0(1.4)$ & $35.1(4.7)$ & $16.6(1.4)$
\end{tabular}

The data are means and SEMs (in parentheses). 
SENSORY RESPONSE GRIDS
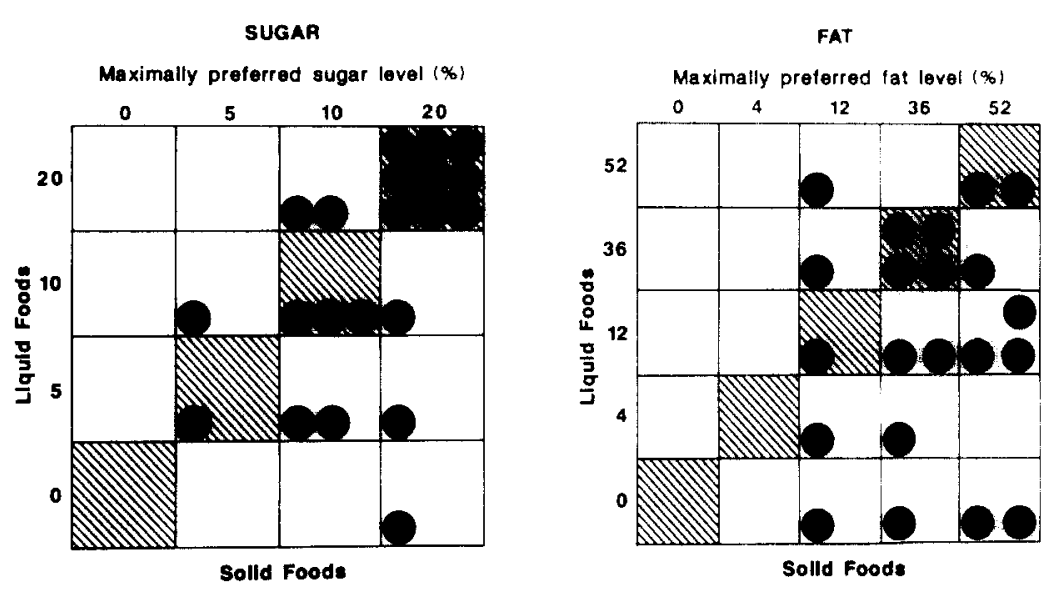

FIG. 5. Sugar and Fat Response Grid showing maximum hedonic responses of individual subjects as a function of stimulus sugar and fat levels. Optimal levels of sugar and fat in liquid foods (Test $\mathrm{A}$ ) are plotted along the y-axis. Optimal levels of sugar and fat in solid foods (Test B) are plotted along the x-axis. Responses along the diagonal (shaded) represent those subjects who preferred the same levels of sugar or fat on Test A and on Test B.

\section{Sugar and Fat Response Grids}

Maximal hedonic ratings of individual subjects as a function of stimulus sugar levels are summarized in Fig. 5 (left panel). Subjects who gave maximal responses to liquid and solid stimuli containing the same level of sugar are represented along the diagonal of the Response Grid (shaded). Optimally preferred sugar levels in liquid and solid stimuli were highly correlated $(r=.43, p<0.05)$. The subjects generally preferred either the same sugar concentration in both liquids and solids, or the nearest concentration tested. For example, 13 out of 21 subjects selected the same level of sugar in solids (Test B) as in liquids (Test A), while 6/21 selected the next closest level.

Maximal hedonic responses as a function of stimulus fat content are also summarized in Fig. 5 (right panel). Subjects who gave maximal responses to liquid and solid stimuli of comparable fat content are represented along the grid diagonal (shaded). However, the correlation between optimally preferred fat levels in liquid versus solid foods was poor: $r=.02$, ns. The subjects generally preferred solid stimuli of higher fat content than optimally liked in liquid foods. The data show that 12 out of 21 subjects selected higher levels of fat in solids (Test B) then previously rated as optimal in liquids (Test $A$ ). Only $7 / 21$ selected the same level of fat in both liquid and solid foods.

\section{DISCUSSION}

The present data confirm that subjects are capable of judging the increasing sweetness and fat content of liquid mixtures of milk, cream and sugar (10-12). In contrast, assessments of sweetness and fat content were impaired when the same subjects were presented with solid food stimuli containing equivalent amounts of sugar and fat with white bread as an additional component. Despite specific instructions, some subjects were unable to track the increasing fat content of solid foods.
These results are consistent with the sparse data on the oro-sensory assessment of fat-containing foods. Previous studies on the sensory evaluation of dietary fats $(6,16)$ have shown that fat in foods is chiefly detected through texture and mouthfeel. These sensory qualitites are considerably easier to evaluate in liquid than in solid foods. In liquids, oral sensation of stimulus thickness or viscosity may be perceived as denoting elevated fat content. For example, the thickening of cream by gelling (e.g., Devonshire cream) creates the illusion of higher fat content denoting premiumquality product (6). Gelatin-based stabilizers can also act as fat substitutes, as can hydrocolloid thickeners in the aqueous phase of the emulsion. Similarly, the addition of sugar tends to increase solution viscosity, resulting in the perception of enhanced creaminess and elevated fat content. However, the same percepts need not apply to sensory evaluation of fat in solid foods. It remains to be seen whether the assessment of fat in solid or semisolid foods depends to a greater degree on the mechanical properties of the solid, or on some other attributes of texture, mouthfeel or olfaction.

One problem with the sensory evaluation of fats may be linked to the choice of suitable attribute scales for the assessment of fat content in different foods. Only two terms -oily and greasy have been suggested by previous investigators $(4,20)$. Additional terms to describe the mouthfeel of beverages, including thick, creamy, fatty, heavy and syrupy have been provided by Szczesniak (21), while terms for lipid mouthfeel $(14,15)$ usually include such terms as smooth, oily, greasy, waxy, melting, slimy and creamy. Often, textural attributes are less meaningful to subjects than are more abstract qualities: high-calorie, heavy, rich, or fattening (8).

Despite major differences in the perception of stimulus intensity, comparable hedonic response profiles were obtained for both liquid and solid foods. For both sets of foods, hedonic preferences depended on stimulus stugar and fat levels, despite blunted intensity ratings for sweetness and the relative inability to assess the fat content of solid foods. 
Elevated preferences for fat-rich solid foods in the absence of accurate sensory assessment of fat content suggest that food acceptability ratings need not be analytical in nature and do not depend on conscious perception of food constituents (3). The acceptability of fat-rich food and the selection of a high-fat diet need not be linked to an accurate assessment of the fat content of common foods. In this sense, fats can indeed function as "hidden calories" at the initial sensory level.

The stability of acceptability ratings across food systems is a previously unexplored issue. Optimally preferred sugar levels (as distinct from perceived sweetness) were approximately the same for liquid and solid foods. Subjects who liked intensely sweet stimuli on Test A tended to select high levels of sugar on Test B. The optimally preferred level of sweetness appears to be a quality that can be abstracted from one food system to another.

In contrast, the acceptability of dietary fats may be to a large extent system specific. A comparison of liquid and solid foods showed that subjects generally selected solid foods of higher-fat content than previously judged as optimal for liquid foods. It is worth noting that these elevated preferences for high-fat stimuli were coupled with impaired ability to accurately assess product fat content.
The present study may have implications regarding food preferences and diet selection. Excessive fat consumption in the U.S. has been linked to obesity, hyperlipidemia and coronary heart disease. Greater awareness of health issues has resulted in negative attitudes towards foods with a high-fat content (18) and may have led to changes in the consumption of fat-containing foods. The U.S. consumption of high-fat liquid dairy products: whole milk and heavy cream has been declining, while the consumption of sources of hidden fat: cheese, ice cream and frozen desserts has soared. It is tempting to speculate that consumers are merely replacing obvious fat sources with food in which fat is difficult to detect by sensory means. The issue of fat in foods has become more pressing with the introduction of fat substitutes, designed to mimic the mouthfeel of fat without providing the calories. There is need for more work on evaluation and assessment of fat content of foods and its relationship to food preference.

\section{ACKNOWLEDGEMENTS}

This research was supported by NIH grants DK37011, DK 37083 to A.D.; grant F32 MH09003-01 to E.E.S. and grant DK32688 to E.S. and A.J.S.

\section{REFERENCES}

1. Abraham, S. Weight and height of adults 18-74 years of age, United States 1971-1974. Vital and Health Statistic Series 11, no 211. DHEW Publ (PHS) 79-1659. National Center for Health Statistics, Hyattsville, MD, 1979.

2. Beauchamp, G. K.; Cowart, B. J. Development of sweet taste. In: Dubbing, J., ed. Sweetness. Berlin: Springer-Verlag; 1987.

3. Booth, D. A.; Conner, M. T.; Marie, S. Sweetness and food selection: Measurement of sweeteners' effect on acceptance. In: Dobbing, J., ed. Sweetness. Berlin: Springer-Verlag; 1987.

4. Brandt, M. A.; Skinner, E. Z.; Coleman, J. A. Texture profile method. J. Food Sci. 28:404-409; 1963.

5. Cabanac, M.; Duclaux, R. Obesity: absence of satiety aversion to sucrose. Science $168: 496-497 ; 1970$.

6. Cooper, H. R. Texture in dairy products and its sensory evaluation. In: Moskowitz, H. R., ed. Food texture. New York: Marcel Dekker; 1987.

7. Cussler, E. L.; Kokini, J. L.; Weinheimer, R. L.; Moskowitz, H. R. Food texture in the mouth. Food Technol. 33(10):89-92 1979.

8. Drewnowski, A. Fats and food texture: Sensory and hedonic evaluations. In: Moskowitz, H. R., ed. Food texture. New York: Marcel Dekker; 1987

9. Drewnowski, A. Sweetness and obesity. In: Dobbing, J., ed. Sweetness. Berlin: Springer-Verlag; 1987.

10. Drewnowski, A.; Brunzell, J. B.; Sande, K.; Iverius, P. H.; Greenwood, M. R. C. Sweet tooth reconsidered: Taste responsiveness in human obesity. Physiol. Behav. 35:617-622; 1985.

11. Drewnowski, A.; Greenwood, M. R. C. Cream and sugar: Human preferences for high-fat foods. Physiol. Behav. 30:629 $633 ; 1983$.
12. Drewnowski, A.; Halmi, K. A.; Pierce, B.; Gibbs, J.; Smith, G. P. Taste and eating disorders. Am. J. Clin. Nutr. 46:442-450; 1987.

13. Hamilton, E. M. N.; Whitney, E. N. Nutrition. St. Paul, MN: West Publishing Co.; 1982.

14. Jowitt, R. The terminology of food texture. J. Text. Stud. 5:351-358; 1974.

15. Kokini, J. L.; Kaldane, J. B.; Cussler, E. L. Liquid texture perceived in the mouth. J. Text. Stud. 8:195-218; 1977.

16. Pangborn, R. M.; Dunkley, W. L. Sensory discrimination of fat and solids-not-fat in milk. J. Dairy Sci. 47:719-726; 1964.

17. Rodin, J. Psychological factors in obesity. In: Bjorntorp, P.; Cairella, M.; Howard, A. N., eds. Recent advances in obesity research. vol. 3. London: John Libbey; 1980.

18. Shepherd, R.; Stockley, L. Fat consumption and attitudes towards food with a high-fat content. Hum. Nutr. Appl. Nutr. 39A:431-442; 1985.

19. Stellar, E.; Shrager, E. E. Chews and swallows and the microstructure of eating. Am. J. Clin. Nutr. 42:973-982; 1985.

20. Szczesniak, A. S. Classification of textural characteristics. J. Food Sci. 28:385-389; 1963.

21. Szczesniak, A. S. Classification of mouthfeel characteristics of beverages. In: Sherman, P., ed. Food texture and rheology. New York: Academic Press; 1979.

22. Weiffenbach, J. M. Taste and development: The genesis of sweet preference. DHEW Publ. No. (NIH) 77-1068. U.S. Govt. Printing Office, Washington, DC, 1977. 